\title{
New Faculty's Perception of Faculty Development Initiatives at Small Teaching Institutions
}

\author{
Aditi Puri, ${ }^{1}$ Daren Graves, ${ }^{2}$ Arlene Lowenstein, ${ }^{3}$ and Lily Hsu ${ }^{4}$ \\ ${ }^{1}$ Forsyth School of Dental Hygiene, Massachusetts College of Pharmacy and Health Sciences, Boston, MA 02115, USA \\ ${ }^{2}$ Department of Education, Simmons College, Boston, MA 02115, USA \\ ${ }^{3}$ School of Nursing and Health Sciences, Simmons College, Boston, MA 02115, USA \\ ${ }^{4}$ Provost Office, Massachusetts College of Pharmacy and Health Sciences, Boston, MA 02115, USA \\ Correspondence should be addressed to Aditi Puri, apuri80@hotmail.com
}

Received 14 June 2012; Accepted 3 July 2012

Academic Editors: R. Mamlok-Naaman and G. Sideridis

Copyright ( $) 2012$ Aditi Puri et al. This is an open access article distributed under the Creative Commons Attribution License, which permits unrestricted use, distribution, and reproduction in any medium, provided the original work is properly cited.

New faculty at small teaching institutions experience varied challenges related to navigation of three academic pillars: teaching, scholarship, and service. New faculty are often not prepared by doctoral or terminal degree granting institutions for faculty roles. This increases the responsibility of the hiring institution to introduce new faculty to the academic culture and provide development opportunities aimed at promoting academic success. For the purpose of this study seventeen faculty members, employed between one and three years at four northeastern USA colleges, were recruited for interviews. The Motivation-Hygiene Theory was applied to study the impact of challenges, barriers, and facilitators on faculty satisfaction with faculty development initiatives. The qualitative results emphasize a need for institutions to enhance the new faculty development initiatives: comprehensive new faculty orientations, ongoing teaching and learning workshops, mentoring programs, and other methods to facilitate the transition of faculty to the new academic position.

\section{Introduction and Literature Review}

Faculty new to the role of academician are often unprepared by degree granting institutions for the unique challenges of an academic career. Successful navigation of the three academic pillars-teaching, scholarship, and service-is contingent upon effective development of new faculty by higher education institutions. The history of faculty development in the United States can be traced back to the 1960's and 1970's, when an influx in the enrollment of diverse and politically active students led to international endeavors toward improving teaching and learning [1]. Postsecondary education was challenged by sit-ins and protests over "irrelevant courses and uninspired teaching [2]." Thorough knowledge of content was no longer the sole requirement for teaching effectively in higher education institutions. In the early years, faculty development programs in the United States (USA) were funded by grants from private foundations and public agencies. Today, these programs are primarily funded by endowments and university budgets [1].
A survey conducted in 1986 reported that $44 \%$ percent of all four-year institutions had faculty development programs [3]. In the late 80s, Jarvis [4] suggested institutions should promote new faculty development based on his review of a widerange of faculty development programs. Currently extensive numbers of programs are opening across US, but many are closing down due to cuts in budget, administrative changes, and lack of commitment to teaching excellence $[1,5]$. Faculty Development may be defined as an endeavor aimed at promoting faculty success and academic acculturation. Some common forms of faculty development include support through course release time, [6] funding, training, opportunities to network, orientation programs, and workshops on teaching and grant writing. New faculty have identified such support as contributing to their development as scholars and teachers [7].

Research supports the significance of faculty development in preparing members of the academy for faculty roles. [8-16] In a longitudinal study of pretenure faculty, Olsen and Sorcinelli [8] noted that institutional support-in the 
form of providing orientation, mentoring, and resources for research and teaching - can be effective in socializing new faculty. Fink [9] found that new faculty development programs are valuable in reducing the time required for faculty to develop as a fully functioning members of the academic team. In addition, faculty development programs provide an opportunity to enhance faculty recruitment and retention [9, 11, 12]. Murray [17] in a qualitative study found that an institution's sole reliance on the institution had failed to support new faculty in academic acclimation. Senior departmental colleagues as the only source for the support of new faculty members resulted in a failure to fully support new faculty in academic acclimation.

After conducting interviews with new faculty, Sorcinelli [10] recommended that institutions encourage and support junior faculty by initiating new faculty orientation and career development workshops. Boice [11] recommended brief initial orientation followed by lengthier workshops offered on a regular basis through the course of the semester, individual interviews with new faculty, and visit to the classes. While development programs exist, they often come up short of projected goals. Lindbeck and Darnell [12] conducted a study to evaluate orientation activities at 92 small nonresearch 1 institutions to report that basic resources required to orient new faculty to institutions were indeed available. However, the study found that institutions need to provide greater support for elements of a successful professoriate that balance teaching, scholarship, and service. Orientation programs can vary in length, but teaching, general support, and professional development are critical $[12,13]$.

To encourage institutions to invest in junior faculty development, the Lily Endowment Teaching Fellow Program [14] provides a one-year grant to numerous institutions to develop teaching programs. The grant is renewable for up to three-years but the institutions are encouraged to invest in the faculty development programs in increasing amount over the three-year period [14]. Fellowships are granted to six to ten tenure-track faculty with one to five years of experience. The key aspects of the program involves teaching workshops and mentoring from senior faculty. Fall and spring retreats are organized to provide an opportunity for scholars from various campuses to interact with each other and experts in the field [14]. Teaching fellows reported positive long-term impact of this program on teaching $[15,16]$.

1.1. The Role of Mentoring in Faculty Development. The social and intellectual isolation often experienced by new faculty can be addressed by creating formal mentoring programs [13]. Mentoring has been shown to be effective in preparing junior faculty for their new roles. $[4,13,18-22]$ Several specific benefits from mentoring have been identified and proposed by research. Kapustin and Murphy's [18] review of the literature reported that mentoring was associated with high productivity and retention. Zeind et al. [19] studied a mentoring program at a health science institution over the course of five years. Along with an orientation, monthly seminars, and end of semester workshops, mentorship was provided in this program, and it was perceived positively by the participants [19]. After interviewing over 100 prominent professors in the United States, Jarvis [4] recommended that research skills among junior faculty can be promoted via mentoring, among other faculty development activities. Schrodt et al. [20] studied 259 new faculty to report that mentored faculty had greater satisfaction with their socialization in the academic community, and formed deeper connections with their institutions as compared to nonmentored faculty. Mentored faculty received more information regarding promotion, tenure, research, teaching, and service expectations from their departments.

Peer mentoring can be an effective and an inexpensive alternative to the traditional dyadic mentoring model [21]. Junior faculty participants in a year-long peer mentoring program reported satisfaction and were interested in continuing participation the following year [21].

Some research exists on factors that contribute to successful mentoring programs, including the relative value of individual personality traits and aspects of diversity. Boice [22] studied 25 mentor and mentee pairs that were matched in two ways, "traditionally" and "arbitrarily." Traditional pairs were formed when mentors and mentee pairs from the same department self-selected each other. Arbitrarily matched pairs joined junior faculty with mentors from varied departments who were selected based on their ability to balance teaching, and scholarship. Arbitrary pairs were slightly more successful than traditional pairs. Moreover, the success of mentoring programs was found to depend more upon regular meetings rather than on the personalities of mentors and mentees. Although forming the mentor-mentee pair was the most difficult aspect of mentoring, pairs mixed across gender, ethnicity, and discipline were as successful as unmixed pairs [22].

Issues of concern in this field include a recent history of closing down faculty development programs, insufficient funding for such training, and a lack of sufficient research highlighting the significance of faculty development. However, adherents enthusiastically note that growth in this area of human resource development of the academy can potentially positively transform teaching and learning in academia [1].

1.2. Faculty Development in the Health Professions. Faculty development programs are shown to be important for preparing health science faculty for their academic and practice roles [23-27]. New faculty from health profession schools are often unprepared for academic roles due to the primary focus on clinical education. Boyce et al. [23] noted that pharmacy practice faculty were not prepared for career paths that demand productivity in teaching, scholarship, and service [23]. Healthcare educators need to be aware of changes in technology in healthcare practice [24]. An interdisciplinary approach to faculty development can be effective in addressing such needs in training. Faculty who attended an interdisciplinary seminar reported a better understanding of the differences and similarities in the provision of healthcare [25]. In one case study, clinical and teaching 
responsibilities were identified as hurdles to participation; however, the interaction with colleagues, demonstration of departmental support, and resulting intellectual growth made a creative half-day session facilitated participation [26]. Romig et al. [27] carried out a literature review to elicit factors that affected allied health faculty job satisfaction. The frustration and dissatisfaction with the lack of formal guidance for tenure found by this research point to a need for investigating attitudes and perceptions of allied health faculty.

1.3. Theoretical Framework. A number of professions have utilized Motivation Hygiene Theory (MH-T) to conduct research related to job satisfaction. MH-T saw much interest when formulated some 30 years ago. The theory has been utilized by researchers in the professions of medicine, accounting, and engineering, among others, to study job satisfaction $[28,29]$. It has been recently revived particularly in psychology as emerging research in this discipline has supported its basic tenets [30]. The research described below examines its relevance to the study of satisfaction of new faculty with faculty development initiatives and the effectiveness of such programs.

$\mathrm{MH}-\mathrm{T}$ proposes specific satisfaction and dissatisfaction factors related to employment [28]. Job satisfaction factors include achievement, recognition, the work itself, responsibility, and advancement. Job dissatisfaction factors relate to company policy and administration, interpersonal relations, working conditions, supervision, and salary. The determinants of satisfaction and dissatisfaction were named as "motivators" and "hygienes," respectively.

Herzberg et al. [28] proposed a two-part schema where, on one hand, job satisfaction factors are implicated in doing a job, and on the other hand job dissatisfaction factors are related to the job context. Two psychological dimensions proposed included "satisfaction no satisfaction" and "dissatisfaction no dissatisfaction." The theory argued that "motivators" were elements of employment that contributed along the satisfaction no satisfaction scale, and "hygienes" were elements that contributed to dissatisfaction-no dissatisfaction scale. The presence of motivators was associated with high levels of satisfaction. The absence of motivators did not cause dissatisfaction, but led to no satisfaction. Similarly, absence of hygienes was not responsible for satisfaction, but led to no dissatisfaction. This theory provides an understanding of how job satisfaction of new faculty is influenced by the opportunities for academic advancement [29].

\section{Purpose and Methodology}

While most of the research cited above was conducted in large educational institutions, this qualitative study explores both the perception of new faculty toward the effectiveness of faculty development and the actual opportunities offered in small teaching institutions in this area. The job satisfaction and dissatisfaction factors proposed by Herzberg et al. in the motivation-hygiene theory ( $\mathrm{MH}-\mathrm{T})$ have been applied to understand the impact of challenges, barriers, and facilitators as they relate to opportunities for academic growth [28]. Through interviews, the authors explored the value of institutional support for faculty as they navigated through perceived academic challenges.

2.1. Participants and Procedure. Subjects of this study were new faculty recruited from four colleges in a northeastern state of the United States. Faculty were defined as new if they had started working at their institution within the last three years. Participants were recruited via three email invitations for semistructured interviews. Three email reminders enabled researchers to increase the response rate. Interviewees included seventeen new faculty, thirteen women and four men. A potential limitation of the study might be an underrepresentation of male faculty members. While the researchers acknowledges that this gender imbalance might have skewed some gender patterns and these patterns are worth exploring in future research, the goal of this research was not to look through a gendered lens. Participants were drawn from health sciences, library science, and arts and science. The Carnegie classifications of the institutions represented were a special focus institution (special health), two Master's colleges (smaller and larger programs), and a Baccalaureate college (diverse fields) [31]. This was a purposeful sample that sufficiently captured both representativeness or typicality and heterogeneity of this group $[32,33]$. After interviewing majority of the participants it was evident that no new prevalent themes emerged, which Seidman (1998) [33] refers to as saturation of information. While the majority of the participants were from one out of the four institutions and had access to a comprehensive new faculty development program, the rest of the participants lacked access to comprehensive faculty development opportunities. Institutional review board approvals were received from all four institutions.

Questions in semistructured interviews queried background information from participants. This included questions about their journey to their current position, their educational background, and their previous experience in clinical or academic settings. Remaining questions sought to understand how access, or lack of access, to faculty development initiatives impacted their academic growth. Interviews lasted approximately 60 minutes and were recorded and transcribed. The interviews yielded approximately 400 pages (avg. line count of 42) of interview data that was systematically analyzed using Motivation-Hygiene Theory as the theoretical underpinning.

2.2. Data Analysis. All interviews were conducted by the primary author, who, as a new faculty member, was able to access and gain information from participants given congruence in their mutual professional status. On one hand, the primary author's identity as a new faculty was an asset as the participants would likely feel less professionally threatened and assume a sense of empathy by sharing with a fellow new faculty member. On the other hand, the primary author had to account for the possibility that the author's own experiences could unduly impact that data 
analysis. Because of that relationship, it was important for the researcher to make use of "bracketing" to set aside personal interpretations and potential biases prior to beginning the interviews and throughout data analysis. The primary author worked with the other authors, who were not involved with the data collection, to systematically monitor the bracketing process [34]. Descriptive validity was ascertained by recording and transcribing the interviews verbatim. Deductive codes emerged from the theories in the research literature, and inductive codes surfaced from unanticipated concepts and themes after a careful reading of the interview data. The coauthors coded the data independently of one another, and then compared the codes and themes to ascertain the interpretative validity of the data. The independently determined codes and themes by co-authors were applied to the raw data after they were compared and verified. The applied codes were compared by the co-authors, and 95\% reliability code application was established.

NVIVO 8 [35] software was utilized to rapidly determine the frequency of the codes. The codes and themes that emerged from the data were compared to the key concepts in MH-T to determine theoretical validity. The MH-T was utilized as a framework to determine how self-reported experiences of new faculty members influenced their job satisfaction.

\section{Results}

Results relying on MH-T to develop themes within the thematic categories of challenges, barriers, and facilitators are discussed below. They are summarized in Table 1. These results are based on a sample of 17 , who agreed to participate in the interview, out of total of 30 potential participants.

\subsection{Challenges: Access to Comprehensive Programs and Formal} Mentors. Challenge was an unanticipated code that emerged from close reading of the concepts grounded in the narrative data. Challenge is defined as participant identification of an existing problem around navigating the professional culture and requirements of the faculty position. The participants identified two major challenges, access to comprehensive new faculty development and formal mentoring.

3.1.1. New Faculty Development Program. Three of the four institutions in this study lacked a comprehensive new faculty development program. According to participants, comprehensive support for promotion/tenure, teaching, and scholarship was lacking. New faculty orientation programs at the majority of these institutions were limited to human resource issues. As one participant put it "we had an orientation for new faculty but... it was kind of like, you know, an HR type video" (Participant number 9, or P9). Another participant (11) desired access to comprehensive new faculty development opportunities, but was disappointed:

Well, that's something that I would hope would be enhanced. New faculty orientation, I mean it is couple of days at least on the calendar, but really it was a morning with some people in the administration and it was more structured along the lines of the nuts and bolts of human resources... but I would have liked more in terms of... explaining the process of probation and development and what they are looking for and how they gauge success year after year. I would have liked more of that because I found you can get that by asking colleagues and asking your chair, but I think it would be a good thing to see more of that upfront for new faculty.

The participant felt that the brief orientation provided by the institutions lacked information about yearly evaluations, promotion, or the tenure process. Others indicated that institutions failed to provide access to initiatives targeted towards supporting faculty in their teaching and scholarship endeavors. Discontent was evident in the words of one participant:

\section{I think there is [are] okay resources around teaching, but it could be better. Well, periodically, they will have a continuing program and the next one with college is in October. . I would like to see that a little more consistently. . . but I would like to see a little more comprehensive around teaching. Around research, the support is awful. (P13)}

This participant's words seem to indicate that he/she feels that short orientations focused on human resource issues were ineffective in preparing faculty to address teaching and scholarship challenges. Information about promotion/tenure and yearly evaluation would have better prepared faculty to navigate institutional challenges.

3.1.2. Lack of Formal Mentors. Mentors support faculty in navigating the complexity of academic institutions and thus can be instrumental to faculty success. Schrodt et al. [20] found that mentored faculty had greater satisfaction with acculturation in the academic community. The majority of the institutions in the current study lacked a formal mentoring program. In the current study, $70 \%$ of new faculty desired access to formal mentoring. A few faculty reported access to informal mentors but would have preferred to participate in formal mentoring at their institutions. When one participant was asked about her/his access to formal or informal mentors, the response was

I have not had any and I would like to be
involved in this mentorship [mentoring] program.
I have not had any unofficial [informal] mentor..
No I never had any mentor, unfortunately. I
would like to... to be enrolled and engaged in
mentorship [mentoring] program. I would love to
have anybody... whether from my discipline or
a different discipline to mentor me. It would be
encouraging to me and motivating and keeps me
going and make sure that I am doing the right
things. (P10)

Faculty expressed that formal mentors would enable them to understand the complexity of their institution and 
TABLE 1: Themes and subthemes derived from qualitative analysis.

\begin{tabular}{|c|c|c|c|}
\hline Themes & Institutional challenges subthemes & Barriers subthemes & Facilitators subtheme \\
\hline $\begin{array}{l}\text { Faculty } \\
\text { development } \\
\text { programs }\end{array}$ & $\begin{array}{l}\text { New faculty development program } \\
\text { (i) Lack of support for } \\
\text { promotion/tenure } \\
\text { P11: "Well, that's something that I } \\
\text { would hope would be enhanced. New } \\
\text { faculty orientation, I mean it is couple of } \\
\text { days at least on the calendar, but really it } \\
\text { was a morning with some people in the } \\
\text { administration and it was more } \\
\text { structured along the lines of the nuts and } \\
\text { bolts of human resources... but I would } \\
\text { have liked more in terms of... explaining } \\
\text { the process of probation and } \\
\text { development and what they are looking } \\
\text { for and how they gauge success year after } \\
\text { year. I would have liked more of that } \\
\text { because I found you can get that by } \\
\text { asking colleagues and asking your chair, } \\
\text { but I think it would be a good thing to see } \\
\text { more of that upfront for new faculty." } \\
\text { (ii) Lack of support for teaching and } \\
\text { scholarship } \\
\text { P13: "I think there is [are] okay resources } \\
\text { around teaching, but it could be better. } \\
\text { Well, periodically, they will have a } \\
\text { continuing program and the next one } \\
\text { with college is in October... I would like } \\
\text { to see that a little more consistently... } \\
\text { but I would like to see a little more } \\
\text { comprehensive around teaching. Around } \\
\text { research, the support is awful." } \\
\text { (iii) Lack of formal mentoring } \\
\text { (ivowo ... tenureship \{sic\}, I need to } \\
\text { means, how you get there, and if I had a } \\
\text { mentor in or out of the department, I } \\
\text { could ask them those question[s]...." } \\
\text { like to be involved in this mentorship } \\
\text { [mentoring] program. I have not had } \\
\text { any unofficial [informal] mentor... No I } \\
\text { never had any mentor, unfortunately. I } \\
\text { would like to... to be enrolled and } \\
\text { engaged in mentorship [mentoring] } \\
\text { program. I would love to have } \\
\text { anybody... whether from my discipline } \\
\text { or a different discipline to mentor me. It } \\
\text { would be encouraging to me and } \\
\text { motivating and keeps me going and } \\
\text { make sure that I am doing the right } \\
\text { things." }\end{array}$ & $\begin{array}{l}\text { New faculty orientation program } \\
\text { (i) Time constraints from teaching } \\
\text { P5: "I think NFO is a valuable } \\
\text { component that the college is initiating. } \\
\text { But it's a limitation for myself... it would } \\
\text { be wonderful to have it at a different } \\
\text { time in order to make it more feasible to } \\
\text { get to." } \\
\text { (ii) Curriculum sequence } \\
\text { P4: "the active learning that was first } \\
\text { introduced in NFO was extremely } \\
\text { helpful... I would have liked to see it } \\
\text { earlier in our curriculum." }\end{array}$ & $\begin{array}{l}\text { Mentorship } \\
\text { (i) Access to formal/informal on- or } \\
\text { off-campus mentors } \\
\text { P9: "I have had some kind of informal } \\
\text { mentorship with Dr. [XXX] and I think } \\
\text { that has been wonderful." } \\
\text { P7: "I do have mentors informally also, } \\
\text { outside of the college that I consult. There } \\
\text { are colleagues... I went to graduate } \\
\text { school with, at other institutions and in } \\
\text { other positions, so I call them up... about } \\
\text { this... issue and solicit suggestions and } \\
\text { ideas from them. And if I have a question } \\
\text { or suggestion about teaching, I don 't } \\
\text { hesitate to talk to those folks. So yeah, I } \\
\text { would say... the quality of the } \\
\text { relationship is excellent." } \\
\text { New faculty orientation program } \\
\text { (i) Positive learning experience } \\
\text { P7: "the last meeting we had about } \\
\text { grants, I know I am moving into the } \\
\text { second year of my appointment. So, it's } \\
\text { time... for me to start thinking about } \\
\text { writing a grant. But I had no ideas, how } \\
\text { to start, where to send it, where to look, } \\
\text { but with that information, it made it } \\
\text { easier and now [I] kind of have some } \\
\text { information about where to start. I think } \\
\text { that was a very very wonderful resource." } \\
\text { (ii) Opportunity to interact with } \\
\text { interdisciplinary faculty } \\
\text { P2: "what I liked best about } \\
\text { [NFO]...was having those people talk } \\
\text { about their experiences and [being] able } \\
\text { to ask how did you teach... did it work } \\
\text { for you or not... I think that helps, } \\
\text { having the perspective from different } \\
\text { colleagues.... It was more like I felt I am } \\
\text { in good company and I can ask stupid } \\
\text { questions, they are not going to go 'why } \\
\text { did you not know that,' 'how did you get } \\
\text { the job without knowing." " }\end{array}$ \\
\hline
\end{tabular}


motivate them to achieve their academic goals. Moreover, they saw easy access to a formal institutional mentoring program as motivating for them to seek assistance, as opposed to searching for external mentors:

I think that there should be [a mentoring program] set up and that you should be able to use it as needed because some faculty may be more timid or shy or whatever about seeking informal supervision. Where if they had that already put in that mechanism they would be more likely to use it. (P9)

Faculty stated that formal mentoring would encourage faculty to seek assistance from mentors early in their career, instead of waiting until the proximity of tenure. Yet faculty were also keen on additionally seeking formal mentoring from interdisciplinary faculty, “...tenureship $\{$ sic $\}$, I need to know more about that and what that means, how you get there, and if I had a mentor in or out of the department, I could ask them those question [s]...." (P14)

Looking at the ways the participants talk about new faculty development and formal mentoring, illuminates how participants identify existing problems around navigating the professional culture and requirements of their faculty positions.

3.2. Facilitators - New Faculty Orientation (NFO) Programs and Mentorship. Facilitators are derived from the Motivation Hygiene Theory in the areas of satisfaction and no dissatisfaction factors. The facilitators are defined as variable factors that make navigation of the aforementioned challenges easier. Participants identified two major facilitators, positive learning experiences, and opportunities to interact with interdisciplinary peers within new faculty and access to formal/informal on or off campus mentors.

3.2.1. New Faculty Orientation (NFO). Only one institution in this study offered a comprehensive NFO program that ran throughout the academic year. The NFO Program comprised of monthly sessions that included presentations on topics relevant to faculty success and peer discussion. Topics included learner-centered teaching, classroom management, grant writing, institutional review board, and research methodology, among others. Study participants who had access to informal mentors perceived that as enhancing their academic goals. They felt these resources prepared them to navigate the academic system and prepared them for the role of a teacher and a scholar.

The program was perceived as a facilitator in that sessions, resources, and peer discussions contributed towards a positive learning experience and increased opportunities for interaction with interdisciplinary faculty. The NFO was perceived positively by $83 \%$ of the participating faculty. Fiftyeight percent of the participating faculty appreciated the opportunity to interact with interdisciplinary peers:

what I liked best about [NFO]... was having those people talk about their experiences and [being] able to ask how did you teach. .. did it work for you or not... I think that helps, having the perspective from different colleagues.... It was more like I felt I am in good company and I can ask stupid questions, they are not going to go "why did you not know that", "how did you get the job without knowing." (P2)

Another participant learned strategies to manage a large classroom and valued the peer support provided by the program, "the other challenge was managing bigger classes and again I think we had NFO session, they talked about things you need to manage bigger classes... After talking and coming to meeting [s] and listening to what other people do, I started feeling... comfortable and in control of big classes" (P7). This participant valued support for grant writing received from the NFO program:

the last meeting we had about grants, I know I am
moving into the second year of my appointment.
So, it's time... for me to start thinking about
writing a grant. But I had no ideas, how to start,
where to send it, where to look, but with that
information, it made it easier and now [I] kind
of have some information about where to start.
I think that was a very very wonderful resource.
(P7)

3.2.2. Mentorship. In addition to NFO support, informal mentoring within or outside the department was valued by faculty as they had one-on-one guidance for teaching and scholarship. In the present study, $76 \%$ faculty had access to formal or informal on-campus mentors within their institution, and 59\% had informal mentors outside the institution. The informal mentors were identified by participants as senior colleagues, professors/advisors from graduate programs, and external research collaborators or faculty peers within or outside the institution. Faculty found fulfillment in these relationships and valued the support they received:

"I have had some kind of informal mentorship with Dr. [XXX] and I think that has been wonderful." (P9) I do have mentors informally also, outside of the college that I consult. There are colleagues... I went to graduate school with, at other institutions and in other positions, so I call them up... about this... issue and solicit suggestions and ideas from them. And if I have a question or suggestion about teaching, I donot hesitate to talk to those folks. So yeah, I would say... the quality of the relationship is excellent. (P7)

Faculty did not hesitate in seeking guidance from their mentors for teaching and scholarship because they found their mentors approachable. Mentors' knowledge and experience with regard to research guided and inspired faculty to optimize their potential: "[She] very seasoned in what she is doing, in terms of especially research, which has been a very good mentor to have in that area especially. So yes I have had good opportunities with mentors." (P5) 
Participants noted access to comprehensive new faculty orientation programs and formal/informal mentors significant to their professional growth. The aforementioned factors facilitated navigation of noted challenges.

3.3. Barriers: Time Constraints from Teaching and Curriculum Sequence of NFO. Barriers are derived from the Motivation Hygiene Theory in the areas of no satisfaction and dissatisfaction factors. The barriers are defined as variable factors that make navigation of the aforementioned challenges more difficult. While some of the participants' institutions lacked comprehensive development program, those participants that were exposed to comprehensive faculty development described barriers to taking advantage of the faculty development offerings.

3.3.1. Time Constraints from Teaching. New faculty identified time constraints stemming from their teaching and curriculum sequence as limiting their ability to take full advantage of new faculty orientation (NFO) programs. At one of the institutions, participants of NFO program mentioned time conflict as a major barrier to participation, "well I think those meetings on Fridays are really good and, I almost couldn't go because I am teaching in the lab... I couldn't go at all last year and this is an exception that I am able to go" (P16). Time conflict with didactic or clinical teaching responsibilities prevented some faculty from participating in such programs. Sometimes they had to miss a number of sessions due to this kind of time conflict. One participant recommended offering the program in the off-teaching hours to increase access "I think NFO is a valuable component that the college is initiating. But it's a limitation for myself. . .it would be wonderful to have it at a different time in order to make it more feasible to get to" (P5).

3.3.2. Curriculum Sequence. Faculty also reported concerns with the curriculum sequence and would have preferred to have some sessions early in the academic year, "the active learning that was first introduced in NFO was extremely helpful... I would have liked to see it earlier in our curriculum" (P4). Similarly, another participant mentioned concerns about the curriculum sequence, "looking at the schedule that we have at the faculty orientation, I prefer to get information at the beginning, so that way I will know that I can use it later... oh I would like to learn about that now, not in April" (P17). Participants believed that an alteration in the sequence would have better prepared them to resolve issues they encountered during the academic year.

The participants' responses regarding the roles of time and curriculum sequence illuminate how faculty perceive the impact of barriers in successful navigation of professional challenges.

\section{Discussion and Implications for Institutions/New Faculty}

The key concepts in the MH-T were utilized to understand the impact of barriers and facilitators in the navigation of challenges related to insufficient faculty development opportunities. In this section, we employed $\mathrm{MH}$-T to determine the impact of barriers and facilitators on new faculty satisfaction. Facilitators, as enumerated by faculty in this study, relate to "satisfaction" and "no dissatisfaction" factors in the MH-T theory, whereas the barriers relate to "dissatisfaction" or "no satisfaction."

\subsection{Summary of Challenges}

4.1.1. Faculty Development. Lack of comprehensive faculty development opportunities at a majority of the institutions presented a challenge to the faculty. New faculty orientations that focused on human resource procedures were not valued by faculty, who instead desired information related to teaching, scholarship, and promotion/tenure process. Even faculty who had substantial teaching experience, or had returned to academia after experimenting in other related fields, were interested in participating in comprehensive faculty development programs that focused on issues related to teaching, scholarship, promotion/tenure, and academic acculturation. Their needs resonated with recommendations in the literature that called for the development of new faculty for their roles [8-16].

4.1.2. Mentoring Programs. The faculty in this study reported that minimal access to formal mentoring was also a challenge. They also communicated their need for guidance regarding the tenure/promotion process from a formal mentor. Easier access to formal mentoring opportunities can motivate faculty to seek support early in their careers instead of waiting until the proximity of promotion/tenure decision. Institutions can adopt a traditional mentoring model, where a new faculty is matched with an established senior member. They can also promote mixed pairs across academic discipline to shift the focus from the discipline to academic acculturation and development of the new faculty. In this study faculty desired access to formal mentoring from interdisciplinary mentors and did not see it as a hindrance to their success within their discipline. Similarly, as Boice [22] noted, mentor-mentee pairs mixed across ethnicity, gender, and discipline were as successful as unmixed pairs.

\subsection{Summary of Barriers}

4.2.1. New Faculty Orientation: Time and Curriculum Sequence. There was only one comprehensive new faculty orientation program that was perceived enthusiastically by faculty. They identified barriers that impacted faculty participation due to time conflicts and the sequence of pedagogical issues. Faculty were dissatisfied with the placement of pedagogy in the program and preferred this information to be discussed earlier in the curriculum sequence. These barriers relate to the "working condition" dissatisfaction factor proposed by the MH-T, [28] which refers to facilities available at work. Barriers can be removed by expanding 
Human resource-based orientations to develop comprehensive new faculty orientation programs. These can be instrumental in providing consistent support in the first academic year. These programs need to include initial orientation and ongoing workshops that provide resources essential to navigate teaching, scholarship, and service challenges. Peer support from interdisciplinary and senior faculty can be effective in socializing faculty to the academic culture. The curriculum sequence should be designed to address the pertinent needs of the new faculty cohort. An initial needs assessment might be instrumental in gathering required information. Conflict with academic responsibilities can be addressed by offering incentives such as course release, evening sessions, and stipends, among others. In addition to teaching and scholarship initiatives, the results of this study indicate that NFO programs need to prepare faculty for the impending promotion/tenure decisions by providing structured guidance specific to department and institutional expectations.

\subsection{Summary of Facilitators}

4.3.1. New Faculty Orientation Resources. According to MH$\mathrm{T}$, "advancement" (a change of position or status of the employee in the company) and "working conditions" are considered satisfaction and dissatisfaction factors, respectively. NFO programs provided opportunities for future advancement among new faculty, which according to $\mathrm{MH}$ $\mathrm{T}$ would result in an increase in satisfaction (and thus functioning as an MH-T “facilitator"). Some NFO programs were found to improve working conditions and led to no dissatisfaction [28]. In her study Boyden [13] recommended the development of new faculty development programs like orientations, mentoring and formal support for research, teaching and scholarship. These programs need to provide an opportunity to new faculty to interact with experienced and peer faculty at the institution. The qualitative data obtained in this study indicated that faculty were satisfied with the resources and development opportunities offered by the comprehensive new faculty orientation program at one of the institutions. Faculty appreciated the opportunity to interact and learn from interdisciplinary peers. Comprehensive long-term programs can provide varied opportunities for academic growth. Finally, institutions need to focus on creating an environment where faculty can safely discuss their academic concerns within the confines of the program.

4.3.2. Mentoring. Access to formal and informal mentors within or outside the campus was considered a "facilitator" and related to advancement. Mentorship was correlated to be a "satisfaction" factor advancement, a "no dissatisfaction" working condition [28]. The majority of faculty in this study were satisfied with informal mentors, either within or outside their campus. These mentors provided them with practical tips to navigate teaching, scholarship, and service challenges. Similarly, Schrodt et al. [20] reported that mentored faculty had greater satisfaction with socialization at their academic institutions as compared to nonmentored faculty. Administrators need to encourage faculty to seek mentors outside the discipline and/or their institution to promote scholarship collaborations, teaching excellence, and broader academic perspectives. Informal mentors can be instrumental in the socialization of new faculty to academic cultures when institutions lack comprehensive faculty development or mentoring opportunities within their own campus.

\section{Conclusions and Recommendations}

Small teaching institutions tend to privilege teaching quality as criterion for individual faculty success and the larger institutional goals of the college. These institutions, and others that value teaching quality, have the responsibility to empower faculty by providing access to development opportunities that will enable them to achieve academic success and satisfaction. While research institutions may have teaching/learning centers or other means to provide faculty development, small teaching institutions often do not provide access to those resources. Those institutions that lack access to these opportunities can partner with schools of education to provide this training and encourage faculty to participate in pedagogical development found outside of their institutions.

The authors recommend that institutions establish comprehensive new faculty development programs focused on preparing faculty for academic challenges, including workshops on pedagogy, the tenure/promotion process, grant writing, writing, classroom management, and research methodology, among others. Increasing collaboration with on- and off-campus mentors can provide access to varied interdisciplinary scholarship and development opportunities.

These conclusions are timely, as academic institutions in the United States need to develop creative strategies to attract and retain new faculty in light of the imminent retirement of the Baby Boomer generation. This paper adds to the limited knowledge about the significance of faculty development initiatives in supporting faculty growth in small institutions. Interventions for improving faculty development programs hold much promise for the advancement of both academic institutions and faculty.

\section{Acknowledgments}

A. Puri thanks Dr. Michelle Kalis, Dr. Mary Deane Sorcinelli, Dr. Lind Boyd and Dr. Kaushik Dutta for invaluable suggestions and careful reading of the paper. The study participants are thanked for their significant contribution.

\section{References}

[1] K. G. Lewis, "Pathways toward improving teaching and learning in higher education: International context and background," New Directions for Teaching and Learning, no. 122, pp. 13-23, 2010. 
[2] J. G. Gaff and R. D. Simpson, "Faculty development in the United States," Innovative Higher Education, vol. 18, no. 3, pp. 167-176, 1994.

[3] J. A. Centra, "Faculty development practices in United States Colleges and Universities," Project Report 76-30, Educational Testing Services, Princeton, NJ, USA, 1976.

[4] D. K. Jarvis, “Improving junior faculty scholarship," NewDirections for Teaching and Learning 50:63-72, Jossey Bass, San Francisco, Calif, USA, 1992.

[5] M. D. Sorcinelli, A. E. Austin, P. L. Eddy, and A. I. Beach, Creating the Future of Faculty Development: Learning from the Past, Understanding the Present, Anker Publishing Company, Bolton, Mass, USA, 2006.

[6] M. D. Cox, "The development of new and junior faculty," in Teaching Improvement Practices: Successful Strategies for Higher Education, W. A. Wright, Ed., pp. 283-310, Anker Publishing Company, Bolton, Mass, USA, 1995.

[7] M. D. Sorcinelli, "Effective approaches to new faculty development," Journal of Counseling \& Development, vol. 72, no. 5, pp. 474-479, 1994.

[8] D. Olsen and M. D. Sorcinelli, “. The pretenure years: the longitudinal perspective," in New Directions for Teaching and Learning, no. 50, M. D. Sorcinelli and A. E. Austin, Eds., pp. 15-25, Jossey Bass, San Francisco, Calif, USA, 1992.

[9] L. D. Fink, "Orientation programs for new faculty," in NewDirections for Teaching and Learning, no. 50, M. D. Sorcinelli and A. E. Austin, Eds., pp. 39-49, Jossey Bass, San Francisco, Calif, USA, 1992.

[10] M. D. Sorcinelli, "Satisfaction and concerns of new university teacher," To Improve the Academy, vol. 7, pp. 121-133, 1988.

[11] R. Boice, The New Faculty Member, Jossey Bass, San Francisco, Calif, USA, 1992.

[12] R. Lindbeck and D. Darnell, "An investigation of new faculty orientation and support among mid-sized colleges and universities," Academic Leadership, vol. 6, no. 3, 2008.

[13] K. M. Boyden, "Development of new faculty in higher education," Journal of Professional Nursing, vol. 16, no. 2, pp. 104-111, 2000.

[14] A. E. Austin, "Supporting new faculty through a teaching fellowship program," in NewDirections for Teaching and Learning, no. 50, M. D. Sorcinelle and A. E. Austin, Eds., pp. 73-86, Jossey Bass, San Francisco, Calif, USA, 1992.

[15] A. E. Austin, "Supporting the professor as a teacher: an evaluation study of the lily teaching fellow program," in Proceedings of the Annual meeting of Association for the Study of Higher Education, Portland, Ore, USA, 1990.

[16] K. K. List, "The "Conversation" continues: UMass lilly teaching fellows program builds on first ten years," Journal of Faculty Development, vol. 19, no. 2, pp. 57-64, 2004.

[17] J. P. Murray, "New faculty members' perceptions of the academic work life," Journal of Human Behavior in the Social Environment, vol. 17, no. 1-2, pp. 107-128, 2008.

[18] J. F. Kapustin and L. Murphy, "Faculty mentoring in nursing," Advanced Practice Nursing, vol. 8, no. 4, Article ID 582904, 2008.

[19] C. S. Zeind, M. Zdanowicz, K. MacDonald, C. Parkhurst, C. King, and P. Wizwer, "Developing a sustainable faculty mentoring program," American Journal of Pharmaceutical Education, vol. 69, no. 5, p. 100, 2005.

[20] P. Schrodt, C. S. Cawyer, and R. Sanders, "An examination of academic mentoring behaviors and new faculty members' satisfaction with socialization and tenure and promotion processes," Communication Education, vol. 52, no. 1, pp. 1729, 2003.
[21] J. Moss, J. Teshima, and M. Leszcz, "Peer group mentoring of junior faculty," Academic Psychiatry, vol. 32, no. 3, pp. 230235, 2008.

[22] R. Boice, "Lessons learnt about mentoring," NewDirections for Teaching and Learning 50:51-61, Jossey Bass, San Francisco, Calif, USA, 1992.

[23] E. G. Boyce, J. S. Burkiewicz, M. R. Haase et al., "ACCP white paper: essential components of a faculty development program for pharmacy practice faculty.," Pharmacotherapy, vol. 29, no. 1, p. 127, 2009.

[24] A. J. Lowenstein, "Strategies for Innovation," in Innovative Teaching Strategies in Nursing and Related Health Professions, M. J. Bradshaw and A. J. Lowenstein, Eds., pp. 37-48, Jones and Bartlett, Sudbury, Mass, USA, 5ed edition, 2011.

[25] P. J. Enkins, M. B. Harmer, P. T. Pardue, and N. Turcato, "A model for integrated disciplinary approach to clinical faculty development," Journal of Faculty Development, vol. 19, no. 3, pp. 123-130, 2004.

[26] M. Srinivasan, D. D. Pratt, J. Collins et al., "Developing the master educator: cross disciplinary teaching scholars program for human and veterinary medical faculty," Academic Psychiatry, vol. 31, no. 6, pp. 452-464, 2007.

[27] B. Romig, J. O'Sullivan Maillet, and R. M. Denmark, "Factors affecting allied health faculty job satisfaction A literature review," Journal of Allied Health, vol. 40, no. 1, pp. 3-14, 2011.

[28] F. Herzberg, B. Mausner, and B. B. Snyderman, The Motivation to Work, Wiley \& Sons, New Brunswick, NJ, USA, 1959.

[29] R.F. Pagano, "An organizational tool to enhance work motivation-part I," Physician Executive, vol. 19, no. 1, pp. 3943, 1993.

[30] D. A. Sachau, "Resurrecting the motivation-hygiene theory: herzberg and the positive psychology movement," Human Resource Development Review, vol. 6, no. 4, pp. 377-393, 2007.

[31] http://classifications.carnegiefoundation.org/descriptions/basic .php, 2012.

[32] J. A. Maxwell, Qualitative Research Design an Interactive Approach, Sage Publication, Thousands Oaks, Calif, USA, 2ed edition, 2005.

[33] I. Seidman, Interviewing as Qualitative Researcher- A Guide for Researchers in Education and Social Sciences, Teachers College Press, New York, NY, USA, 3ed edition, 1998.

[34] D. F. Polit and C. T. Beck, Essentials of Nursing ResearchAppraising Evidence of Nursing Practice, Lippincott, Williams \& Wilkins, Hangerstown, Md, USA, 7ed edition, 2009.

[35] http://www.qsinternational.com/products_nvivo.aspx, 2012. 

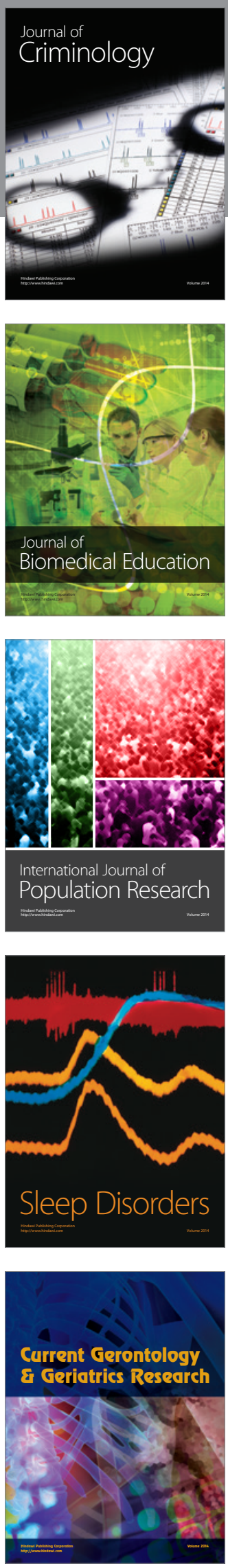
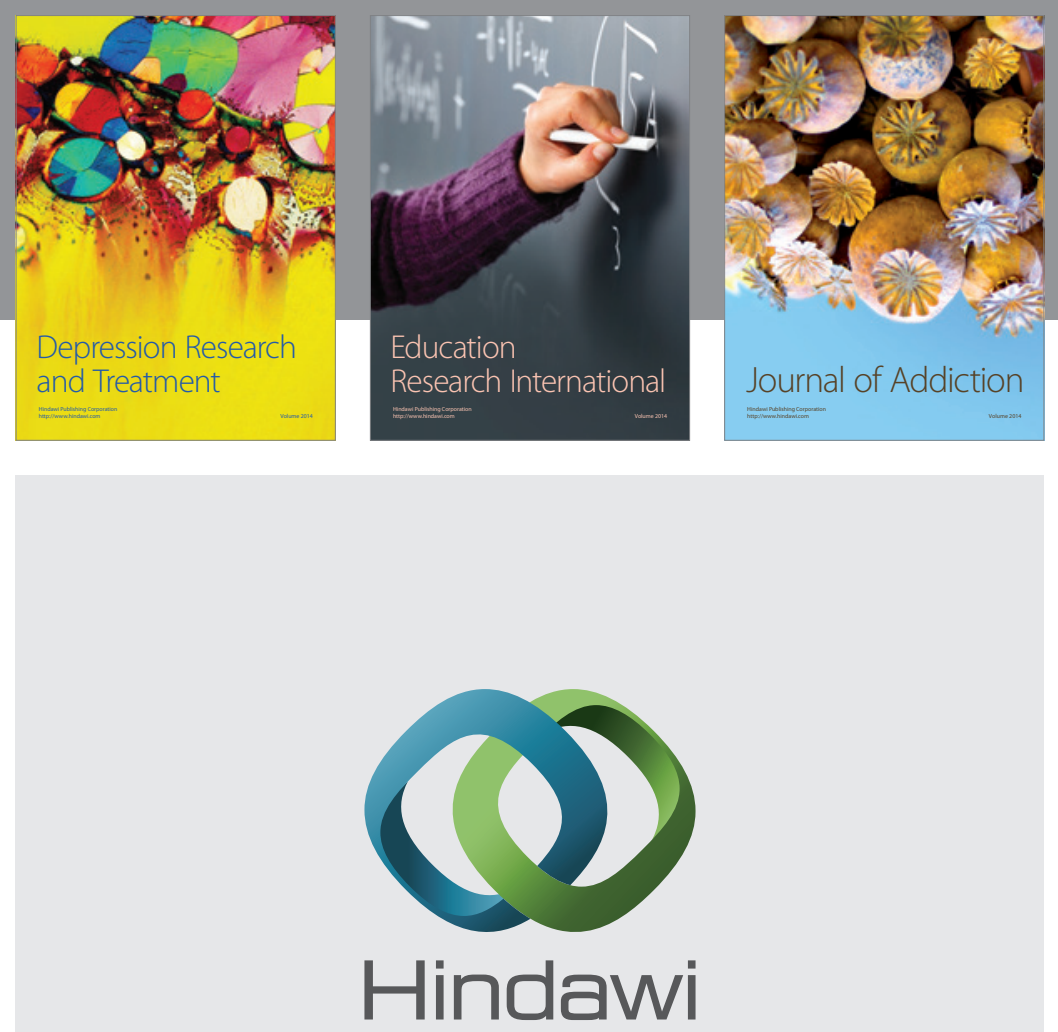

Submit your manuscripts at

http://www.hindawi.com

Child Development Research
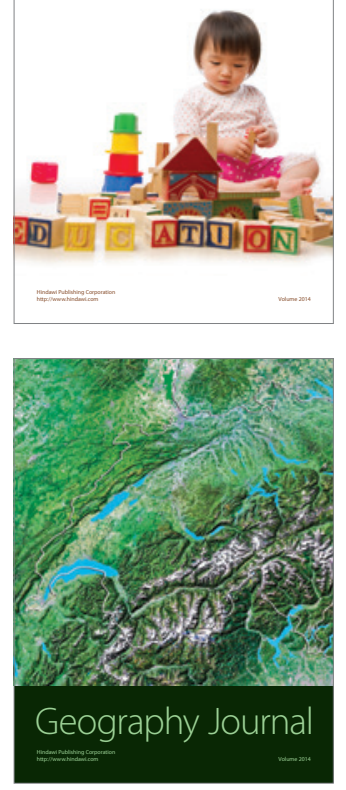

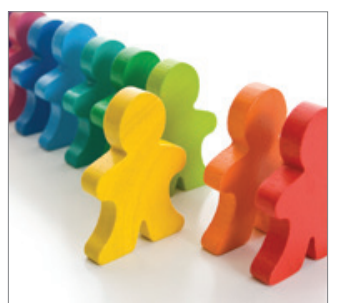

Autism

Research and Treatment
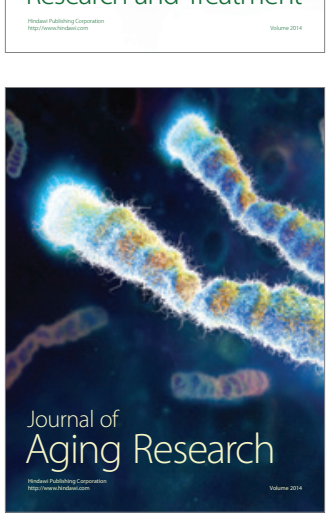
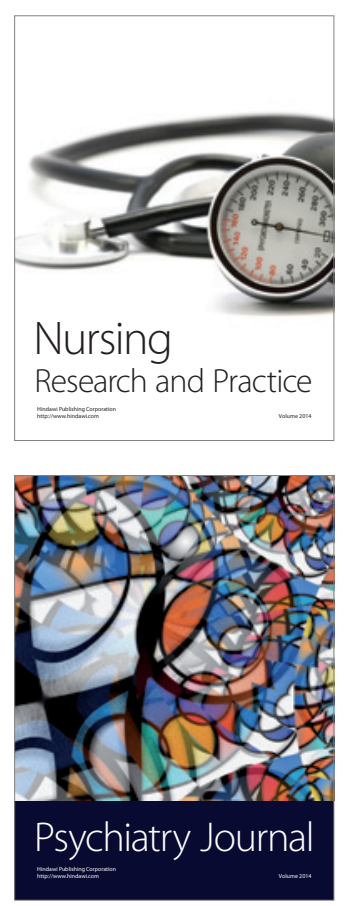
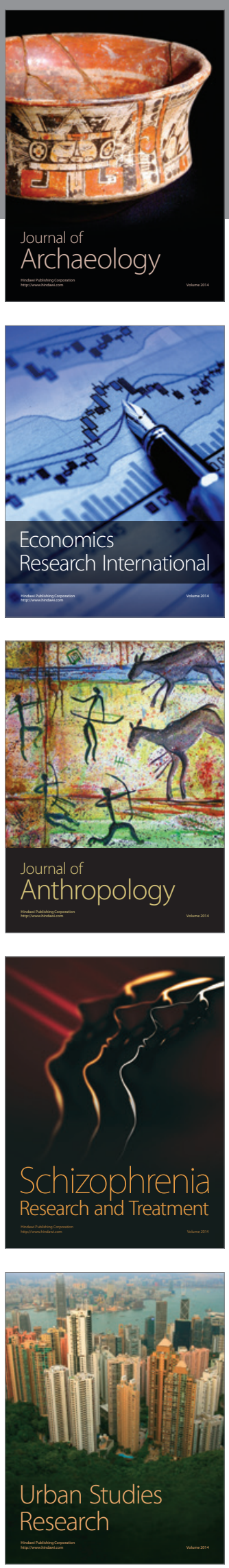